\title{
THE HOLISTIC PERFORMANCE OF AN ENVIRONMENTAL APPROACH: SENEDD CASE STUDY
}

\author{
Fenty Ratna Indarti \\ Department of Architecture, Institute of Technology Sepuluh Nopember, \\ Indonesia \\ e-mail: fenty.ratna@arch.its.ac.id
}

\begin{abstract}
As the awareness of climate change increased, more sustainable designs are available for not only domestic building but also non domestic building. Focusing on integration with the environmental condition of the site, Senedd (The National Assembly of Wales) is designed to embrace nurture the potential of its site. The utilisation of environmental approach on management, energy, water, materials, pollution, health and wellbeing, waste and innovation leads to an excellent BREEAM rating for the building. This paper aims to study the integration of each environmental consideration utilised in the building. The investigation illustrates how the building perform in three aspects: daylight, natural ventilation and thermal comfort. The study represents that a balance of environmental design approach is demonstrated in the building to achieve its best performance by maximising passive strategies instead of active system.
\end{abstract}

Keywords: daylight factor, natural ventilation, thermal comfort, environmental approach; building assessment

\section{INTRODUCTION}

Energy efficiency has become one of the important issues to be considered in designing buildings. Forty percent of global energy consumption produced by the activity in the built environment that contributes to climate change (Schwartz \& Raslan, 2013). In the means of monitoring the energy consumption mitigation, the UK evaluated the energy performance of the building based on asset rating and operational rating (Park et al., 2016). One of the most established building rating tools used to assess building performance in the UK was Building Research Establishment Environmental Assessment Method (BREEAM) which included several sustainability categories for the assessment such as management, energy, water, materials, pollution, health and wellbeing, waste and innovation. There were 6 benchmark classification for BREEAM rating which are outstanding $(\geq 85 \%)$, excellent $(\geq 70 \%)$, very good ( $\geq 55 \%)$, good $(\geq 45 \%)$, pass $(\geq 30 \%)$ and unclassified $(\leq 30 \%)$ (BRE Global, 2016). 
The National Assembly of Wales building (Senedd) had earned an excellent BREEAM certification based on the innovative environmental features. The building is located in Cardiff, UK and designed by Richard Rogers and Ivan Harbours. This achievement echoed the design intention of this building which was designed to have at least a century of life time and became the pioneer in sustainable construction and use. Even though the debating chamber is an enclosed space but the commitment to utilise natural resources is achieved by delivering sunlight through the funnel lantern. The funnel also acts as a chimney where air rose and escapes with helps of wind cowl that turned by the wind so that the warm air escapes on the lee side (Fishlock \& Molyneux, 2010). The fenestration of this building offers an open and transparent feeling and acts as a transitional and sun space for the chamber to trap the heat and protects the chamber from direct contact with the outside. The building consists of three levels. The debating chamber and meeting rooms are located in the ground floor. This paper aimed to investigate the environmental performance of the debating chamber of the Senedd in terms of the daylighting, natural ventilation and thermal conditions.

\section{THEORY / RESEARCH METHODS}

The objective of this research is to investigate the performance of the holistic environmental approach application in the National Assembly of Wales (Senedd). The research limits the study only in the debating chamber, the chamber used by the assembly to have meetings at. Due to limitation of the building access, building simulation was conducted to gain the data needed. A visit to the building before the study helped to understand the actual conditions of the building. Afterwards, a representative model was generated to run the simulation on the daylight, natural ventilation and thermal performance.

This research utilises quantitative methods and all the analysis was based on the numerical data generated by simulation software. Ecotect generated data for the daylight factor of the chamber, Optivent produced data of the natural ventilation performance related to thermal performance and IES-VE administered a further analysis on the room temperature at the specific time. Furthermore, the generated data was analysed to understand how the building performs on the most extreme day of the year. There are three selected dates to run the simulation to serve as a data sample. Those dates represent significant days in terms of environmental conditions. The dates are 21 June representing summer solstice, 20 March representing Equinox and 21 December representing winter solstice. The performance at the selected dates becomes the indicator due to the highest and lowest temperature for the whole year where the building needs to perform as its best.

\section{Daylight Analysis}

People maintain visual contact with the outside environment through window openings where the penetration of daylight into a building takes place (Chel, Tiwari and Chandra, 2009). Hence, sun path diagram is utilised firstly to determine altitude 
based on the latitude of Cardiff. Sun path diagram analysis provides a visual explanation about the penetration of daylight into the internal spaces by using altitude for the corresponding time. Acosta et al. (2015) confirmed that DF expressed the potential illuminance of a room to quantify the daylight allowed by a window. Therefore, for the purpose of this study DF is utilised to determine the internal spaces condition in terms of natural lighting. It is the ratio between the interior illuminance (lux) and the exterior unobstructed illuminance (lux) on a horizontal working plane (Baker \& Steemers, 2002; Chel, Tiwari and Chandra, 2009).

This study utilises a static metrics a simulation criteria. It is used in Radiance as a validated light simulation engine that depends on DF under the Commission Internationale de l'Eclairage (CIE) standard overcast sky (Shakespeare, Larson and Ehrlich, 2005). Simulation of a simplified model (Figure 1) on Ecotect-Radiance provides data of DF (\%) and uniformity ratio. The building plan is divided into 16 points to analyse the distribution of the light inside the chamber. Provided the circular plan of the room and the symmetrical building plan the analysis of the 16 points can represent all sides equally.

A benchmark is employed to determine the state of the daylight analysis. Rizal et al. (2016) conclude that DF of the office building must be between $2 \%$ to $4 \%$. Other consideration to the daylight performance of the Debating Chamber in this study is the CIBSE LG10 Daylight and Window Design. The interpretation of DF scale under the CIE overcast sky is illustrated in Table 1. In terms of daylighting uniformity criteria, a uniformity ratio must achieve at least 0.3 or a minimum point daylight factor of at least 0.3 times the relevant average daylight factor for office buildings (BRE, 2016).

Table 1. The Average Daylight Factor and Uniformity Ratio of The Cases

\begin{tabular}{llll}
\hline DF Value & Under 2\% & Between 2\% and 5\% & Over 5\% \\
\hline Daylight Status & $\begin{array}{l}\text { Not } \\
\text { adequately } \\
\text { lit }\end{array}$ & Adequately lit & Well lit \\
\hline Description & $\begin{array}{l}\text { Artificial } \\
\text { lighting is } \\
\text { required }\end{array}$ & $\begin{array}{l}\text { Artificial lighting } \\
\text { may be needed part } \\
\text { of the time }\end{array}$ & $\begin{array}{l}\text { Artificial lighting is } \\
\text { generally not required, } \\
\text { except at dawn and dusk - } \\
\text { but glare and solar gain may } \\
\text { cause problems }\end{array}$ \\
\hline & & Source: CIBSE, 1999 & \\
\hline
\end{tabular}

\section{Natural Ventilation and Thermal Analysis}

Natural ventilation is passive approach that uses openings to ventilate and cool the building by letting the flow of subaerial air to pass through it (Valinejadshoubia, Heidarib and Zamanib, 2019). It supplies building's occupants with fresh air, cool buildings and keep an agreeable level of air quality if the outdoor environment is conducive (Emmerich, Axley \& Dols, 2001; Heiselberg, 2004).

Circulating air inside buildings can be accomplished by providing differential wind pressure (Olgyay, 1963) and temperature difference to create thermal buoyancy 
(Ghiaus and Allard, 2016). When there are the areas against the wind that hold the positive pressure and the opposite areas with negative pressure, natural ventilation is demonstrated by the wind pressure (Valinejadshoubia, Heidarib and Zamanib, 2019). Thermal buoyancy can be generated by increasing the temperature of one part of the building to solar radiation so that warm air (lower density air) climbs up and the cool air in the adjacent are replaces it until the area achieves thermal equilibrium (Valinejadshoubia, Heidarib and Zamanib, 2019). Due to the pressure difference between the internal and external space, a stack effect is created through the driving force (Moosavi et al., 2018).

To narrow down the analysis, the study assumes the chamber adopts the chimneys (stack effect) mechanism. From this assumption, the inlet is located on the lower part of the wall of the chamber and the outlet is at the top of the chamber that has a bottle-neck-chimney-like shape as depicted in Figure 1. Based on the calculation model, Optivent analyses the natural ventilation based on two scenarios: buoyancy driven and wind + buoyancy driven. Moreover, the study assumes that the wind cowl is inactive to represent the worst scenario for the building to perform passively.

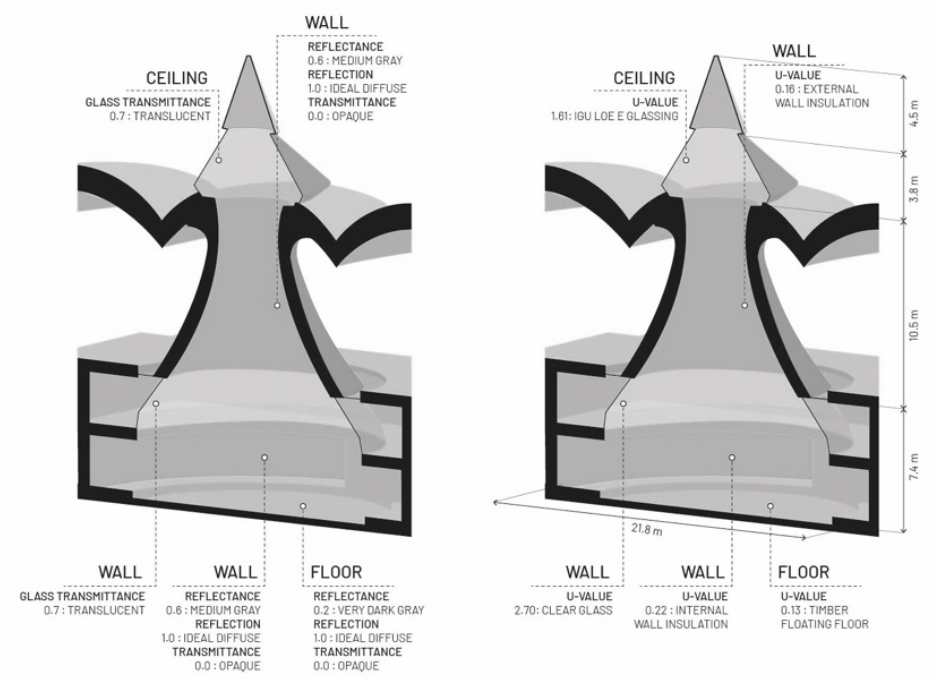

Figure 1. Daylight and thermal calculation model Source: Indarti, 2016

Butcher and Craig (2015) quoted a recommendation of comfort temperature written by CIBSE based on common environmental and physiological factors for nondomestic buildings suggesting a minimum temperature range of $18^{\circ} \mathrm{C}$ (in most nondomestic building types) and maximum of $25^{\circ} \mathrm{C}$ for offices (indoor comfort temperature for non-air conditioned buildings) will satisfy most users.

The study limits the analysis based on the analysis of the thermal performance that relates to natural ventilation. Accordingly, the thermal analysis utilises IES-VE to generate average room temperature during the summer time (May-September) when the natural ventilation is needed the most. The spaces that surround the chamber helps provide a space buffer from the outside environment during the cold days. Despite the benefit during the cold days, the chamber potentially faces overheating 
during the summer (hot days) due to high occupancy and its separation from the outside environment.

\section{RESULTS AND DISCUSSION}

\section{Daylight Performance}

This chapter explained the assessment of daylight performance in the debating chamber by using sun path diagram and Ecotect software. The design concepts tried to deliver natural lighting into the chamber by providing the funnel. After overlaying the sun path diagram on top of the buildings master plan, the solar azimuth and solar altitude was defined based on the opening times of the National Assembly for Wales to investigate the solar penetration inside the chamber by using three key days i.e. summer solstice, equinox, and winter solstice. The building operated from 8 am to 4 pm which means that the sun moved from the east towards the south and set in the west.

Figure 2 illustrates the solar penetration inside the building during summer solstice. Since the building faces south-west, the east elevation receives solar penetration from 8 am to $12 \mathrm{pm}$ while the south elevation receives solar penetration from $1 \mathrm{pm}$ to $3 \mathrm{pm}$. Meanwhile, the west façade only receives solar penetration from $4 \mathrm{pm}$ until the sun sets. In the east elevation, the altitude at 9 am is $45^{\circ}$ and at $12 \mathrm{pm}$ is $63^{0}$. Figure 2 indicates that during summer solstice at $12 \mathrm{pm}$ the solar penetration reaches the debating chamber while in the west elevation when the altitude was $37^{\circ}$ at $4 \mathrm{pm}$ the solar penetration does not reach the debating chamber. The high solar angle from south at $1 \mathrm{pm}$, which is $60^{\circ}$, also penetrates the debating chamber while the $3 \mathrm{pm}$ sun when the altitude is $45^{\circ}$ only reaches the top part of the funnel.
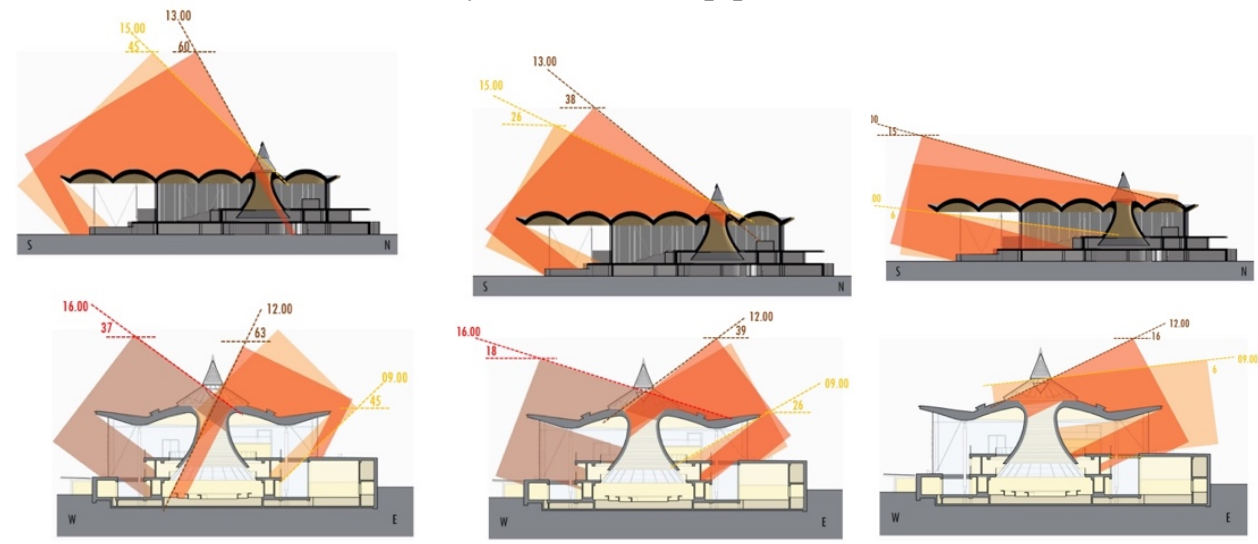

Figure 2. Sun penetration on summer (left), equinox (middle) and winter solstice (right) Source: Indarti, 2016

Figure 2 also depicts the sun path analysis during the equinox where the altitude was $26^{\circ}$ at 9 am and $39^{\circ}$ at $12 \mathrm{pm}$ in the east elevation causing the solar penetration from east does not lit the chamber. The solar penetration from west at $4 \mathrm{pm}$, where 
the altitude is $18^{\circ}$, also does not penetrate the chamber. The solar penetration also stops at the edge of the funnel from south when the altitude is $38^{\circ}$ at $1 \mathrm{pm}$ and $26^{\circ}$ at $3 \mathrm{pm}$. It indicates no direct sun penetration into the chamber during the equinox. In addition, Figure 2 represents the solar penetration during winter which is the lowest altitude throughout the year. In the east elevation the altitude is $6^{0}$ at 9 am and $16^{0}$ at $12 \mathrm{pm}$. Both of these altitudes only fill the Oriel and do not penetrate the chamber. Meanwhile, on the south when the altitude is $15^{\circ}$ at $1 \mathrm{pm}$ and $6^{0}$ at $3 \mathrm{pm}$ the sun only penetrates the Oriel and Neuadd. It indicates that in the winter, the low solar angle does not reach the chamber as well.

The small amount of direct solar penetration indicates that the investigation for the daylight factor in the working plane inside the debating chamber should be carried out to determine whether the debating chamber needs artificial lighting or not. If the average daylight factor in the debating chamber is above $5 \%$, the space does not require artificial lighting and if the average daylight factor in the debating chamber is between $2-5 \%$, the space needs artificial lighting to achieve visual comfort (Rennie \& Parand, 1998). Nevertheless, if the average daylight factor in the debating chamber is under $2 \%$, the space needs full support of artificial lighting.

Three different cases are assessed in this chapter, those are CASE A when the current conditions of the chamber, CASE B when the additional openings in the funnel near the Oriel to provide more solar penetration and CASE Cwhen additional openings in the funnel near the Oriel to provide more solar penetration and removes the wind cowl.

As shown in Table 2 the average daylight factor inside the debating chamber has increased gradually. Case B indicates the improvement by $0.98 \%$ from the current conditions (Case A) meanwhile in the case $\mathrm{C}$ the average daylight factor has improved by $8.99 \%$ from the current conditions (Case A). By increasing the transparent part in the chimney and removing the wind cowl (Case C), the average daylight factor achieves the visual comfort without any support of artificial lighting indicated by the average daylight factor which is $13.07 \%$.

Table 2. The Average Daylight Factor and Uniformity Ratio of The Cases

\begin{tabular}{cccc}
\hline & & Average DF (\%) & Uniformity Ratio \\
\hline 1 & Case A & 4.08 & 0.47 \\
2 & Case B & 5.06 & 0.46 \\
3 & Case C & 13.07 & 0.42 \\
\hline
\end{tabular}

Source: Indarti, 2016

Further analysis is conducted to understand the daylight distribution inside the debating chamber as shown in Figure 3. It depicts the transparent ceiling as the source of the daylight inside the debating chamber. Afterwards it is increased in case B by providing a transparent wall in the down edge of the chimney so that the daylight is distributed evenly. Skylight used in case C, which is the substitute of the wind cowl, helps to provide daylight to the debating chamber as shown in Figure 3.

Case A demonstrates the distribution of the DF in the chamber based on the original condition. The highest percentage of DF is located on point 4 and 13 while 
the lowest is in point 9. Based on Figure 3, the high DF comes from a skylight at the bottom of the tunnel. Moreover, the lowest DF in the middle of the room indicates the tunnel does not deliver enough light into the chamber. Based on this analysis, Case B investigates additional transparent areas of the chamber to increase the DF of the chamber and make it equally distributed. With the additional opening at the lower part of the tunnel the DF is increased significantly at point 4 and 13 whereas the DF at point 9 is still low. From Case A and Case B, the illustrations indicate that the DF of the centre of the room can be increased by adding an opening on the top of the tunnel. Therefore, Case $\mathrm{C}$ illustrates the scenario and indicates a high increase of the DF inside the chamber.
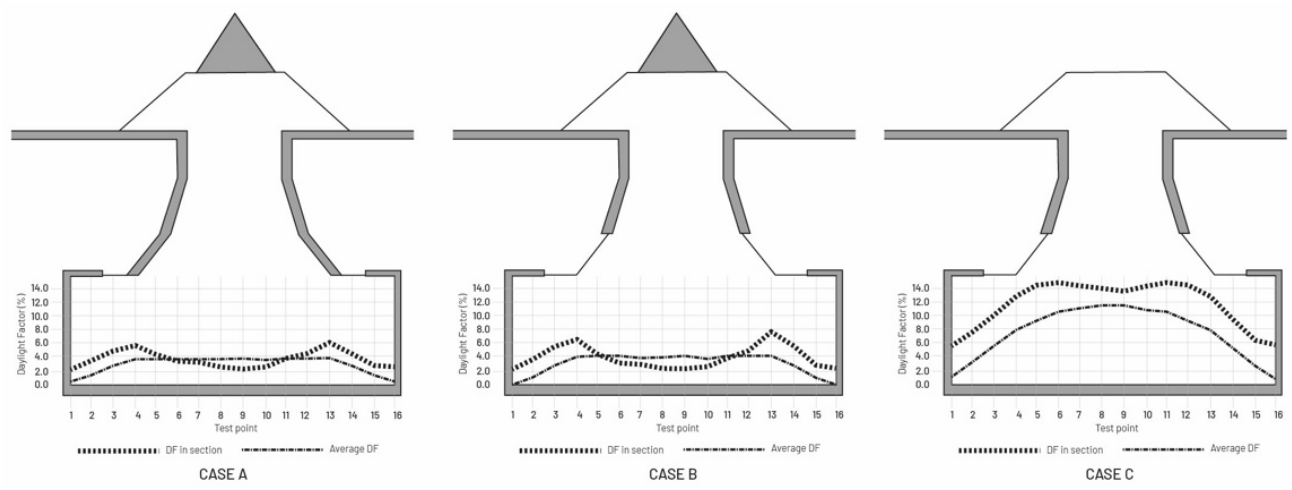

Figure 3. Daylight Factor analysis result Source: Indarti, 2016

Note: The DF is calculated on $750 \mathrm{~mm}$ above the floor to represent the surface of a working table.

\section{Natural Ventilation Performance}

The analysis of temperature profile in Cardiff, UK indicates that during January-April and October-December the temperature is below $18^{\circ}-22^{\circ} \mathrm{C}$ which means that during this time the debating chamber is in heating mode. Meanwhile, during MaySeptember the temperature is approximately between $22^{\circ}-25^{\circ} \mathrm{C}$ which means that the building does not need heating or cooling but potentially overheating inside the room occurs. Natural ventilation is one of the passive ways to mitigate overheating in the building and one of the initial environmental concepts of the building itself.

Investigating the natural ventilation on the hottest day (August) in Optivent software generates the air flow rates that are used for the thermal performance simulation on the next chapter. There are two assessed cases in this chapter that are Case A and Case B. Case A represents the current conditions with the assumptions as follows: the maximum occupancy is 180 people, the artificial lighting is always on and each person is using a computer. On the other hand, case B represents the proposed design where the wind cowl is removed as a consequence of improving daylight inside the chamber. The investigated cases are illustrated in Figure 4. Each case is investigated based on the performance of different effective apertures in the inlet as follows: $25 \%, 50 \%, 75 \%$ and $100 \%$. 
Furthermore, the performance of the natural ventilation system in the debating chamber is illustrated in Table 3 . The results explain that removing the wind cowl causes the mitigation of air flow rate in a small amount. Table 3 also illustrates the achievement of fresh air and cooling requirements for the debating chamber where the results indicate that every case does not achieve the requirements for cooling meanwhile the requirements of fresh air are achieved.
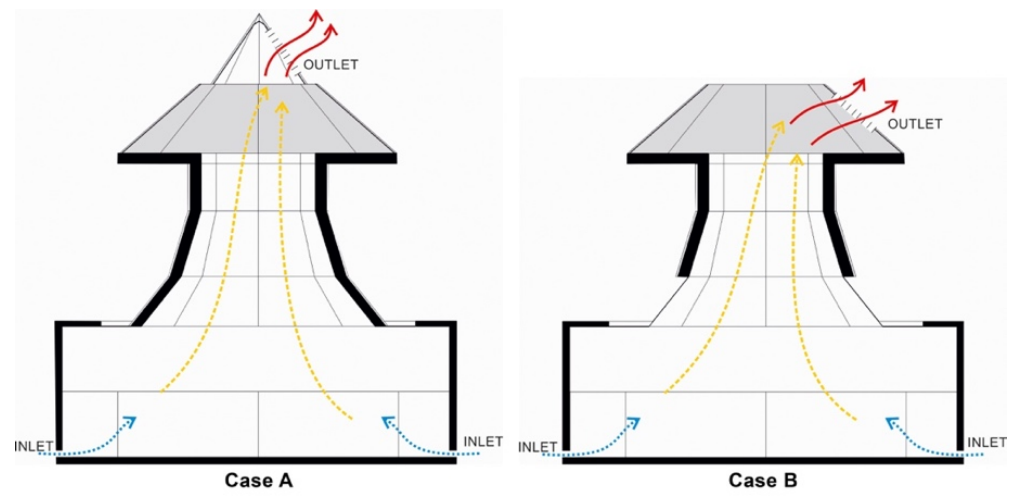

Figure 4. Natural Ventilation Scenario Assumption Source: Indarti, 2016

Table 3. Natural Ventilation Performance of Case A and Case B

\begin{tabular}{lccc}
\hline & $\begin{array}{c}\text { Effective } \\
\text { aperture }\end{array}$ & Case A & Case B \\
\hline Air flow rate (ach) & $25 \%$ & 2.24 & 2.12 \\
& $50 \%$ & 4.49 & 4.23 \\
& $75 \%$ & 6.73 & 6.35 \\
& $100 \%$ & 8.98 & 8.47 \\
\hline Fresh air availability & $25 \%$ & $\bullet$ & $\bullet$ \\
& $50 \%$ & $\bullet$ & $\bullet$ \\
\hline Cooling capability & $75 \%$ & $\bullet$ & $\bullet$ \\
& $100 \%$ & - & - \\
& $25 \%$ & - & - \\
\hline
\end{tabular}

Source: Indarti, 2016

\section{Thermal Performance}

The dynamic thermal simulation aims to analyse the thermal conditions inside the debating chamber during the warm days in May to September using natural ventilation. The evaluation is based on the percentage of hours where the indoor temperature is in the comfort zone, between $22-25^{\circ} \mathrm{C}$ during summer in the working 
hours $(8 \mathrm{am}-4 \mathrm{pm})$. The internal gain of the room is derived from the occupancy level, the artificial lighting and the computer used inside the chamber. For understanding the current conditions of the debating chamber, five different cases are assessed:

1. A - using a wind cowl, maximum occupancy is 180 people, each person is using the computer inside the chamber, artificial lighting is on during working hours, the infiltration rate is 0.25 and no ventilation.

2. A1 - case A assumptions and $25 \%$ effective aperture for the natural ventilation

3. A2 - case A assumptions and 50\% effective aperture for the natural ventilation

4. A3 - case A assumptions and $75 \%$ effective aperture for the natural ventilation

5. A4 - case A assumptions and 100\% effective aperture for the natural ventilation

As a comparison, other five theoretical cases are assessed to investigate thermal conditions of the debating chamber without using wind cowl:

1. B - not using wind cowl, increasing the glazed area on the funnel, maximum occupancy is 180 people, each person is using the computer inside the chamber, artificial lighting is on during working hours, the infiltration rate is 0.25 and no ventilation.

2. B1 - case B assumptions and $25 \%$ effective aperture for the natural ventilation

3. B2 - case B assumptions and 50\% effective aperture for the natural ventilation

4. B3 - case B assumptions and $75 \%$ effective aperture for the natural ventilation

5. B4 - case B assumptions and $100 \%$ effective aperture for the natural ventilation

Table 4 depicts the minimum and maximum temperature inside the debating chamber in the current conditions (using wind cowl, Case A) during summer in five different effective apertures. The results show that the temperature during May to September is decreased along with the bigger aperture provided in the debating chamber for about $1-5^{0} \mathrm{C}$.

Table 4. Minimum and Maximum Temperature of Theoretical Case A

\begin{tabular}{cllllllllll}
\hline \multicolumn{4}{c}{ Min. Temperature $\left({ }^{\mathbf{0}} \mathbf{C}\right)$} & \multicolumn{4}{c}{ Max. Temperature $\left({ }^{\mathbf{0}} \mathbf{C}\right)$} \\
& May & Jun & Jul & Aug & Sept & May & Jun & Jul & Aug & Sept \\
\hline A & 24.5 & 26 & 27.5 & 26 & 25.5 & 34.5 & 34.5 & 36.5 & 34 & 35 \\
A1 & 20.5 & 21.5 & 23.5 & 23.5 & 22 & 29.5 & 31.5 & 32 & 28.5 & 30 \\
A2 & 17 & 17 & 20 & 20 & 18.5 & 29 & 31 & 30 & 29 & 29 \\
A3 & 14.5 & 14.5 & 18 & 18 & 17 & 28 & 30.5 & 30 & 28 & 28.5 \\
A4 & 13 & 13 & 17 & 17 & 17 & 28 & 30 & 30 & 28 & 28 \\
\hline
\end{tabular}

Source: Indarti, 2016

The maximum and minimum temperature inside the debating chamber in the proposed modifications (not using wind cowl and increasing the glazed area in the funnel) during summer in five different conditions is shown in Table 5. The same results appear from the investigation. The bigger the aperture gradually decreases the temperature inside the debating chamber.

By defining the comfort temperature during summer which was between 22$25^{\circ} \mathrm{C}$, the frequencies of achieved thermal comfort inside the debating chamber are 
calculated to compare the annual achievement between using and not using wind cowl to help ventilate the room (see Figure 5).

The results show that the optimum inlet effective aperture for case A (base case) is $50 \%$ indicated by $45.9 \%$ in fully occupied profile and $50.1 \%$ in half occupied profile of working hours during a year the temperature inside the debating chamber is in the comfort zone $\left(22-25^{\circ} \mathrm{C}\right)$ and aperture more than that makes the temperature falls below the comfort zone. Meanwhile, by removing the wind cowl the frequencies of thermal comfort achieved inside the debating chamber increases by $5.6 \%$ in fully occupied profile and $3.2 \%$ in half occupied profile. From these results, the debating chamber performed better by not using wind cowl than by using it during summer, proved by the annual frequencies of thermal comfort achievement during working hours in a year.

Table 5. Minimum and Maximum Temperature of Theoretical Case B

\begin{tabular}{lllllllllll}
\hline & \multicolumn{4}{c}{ Min. Temperature $\left({ }^{\mathbf{C}} \mathbf{C}\right)$} & \multicolumn{5}{c}{ Max. Temperature $\left({ }^{\mathbf{0}} \mathbf{C}\right)$} \\
& May & Jun & Jul & Aug & Sept & May & Jun & Jul & Aug & Sept \\
\hline B & 23.5 & 25 & 26 & 25 & 25.5 & 34 & 34 & 35.5 & 33 & 34 \\
B1 & 20.8 & 22 & 23.5 & 23 & 22 & 29.8 & 31 & 32 & 29.5 & 29.5 \\
B2 & 17 & 17.5 & 20 & 20 & 18.5 & 29 & 30.5 & 30 & 29 & 29.5 \\
B3 & 17 & 17.5 & 20 & 20 & 18 & 29 & 30.5 & 30 & 29 & 29 \\
B4 & 15 & 15 & 19 & 17 & 17 & 29 & 30 & 30 & 29 & 29 \\
\hline
\end{tabular}

Source: Indarti, 2016

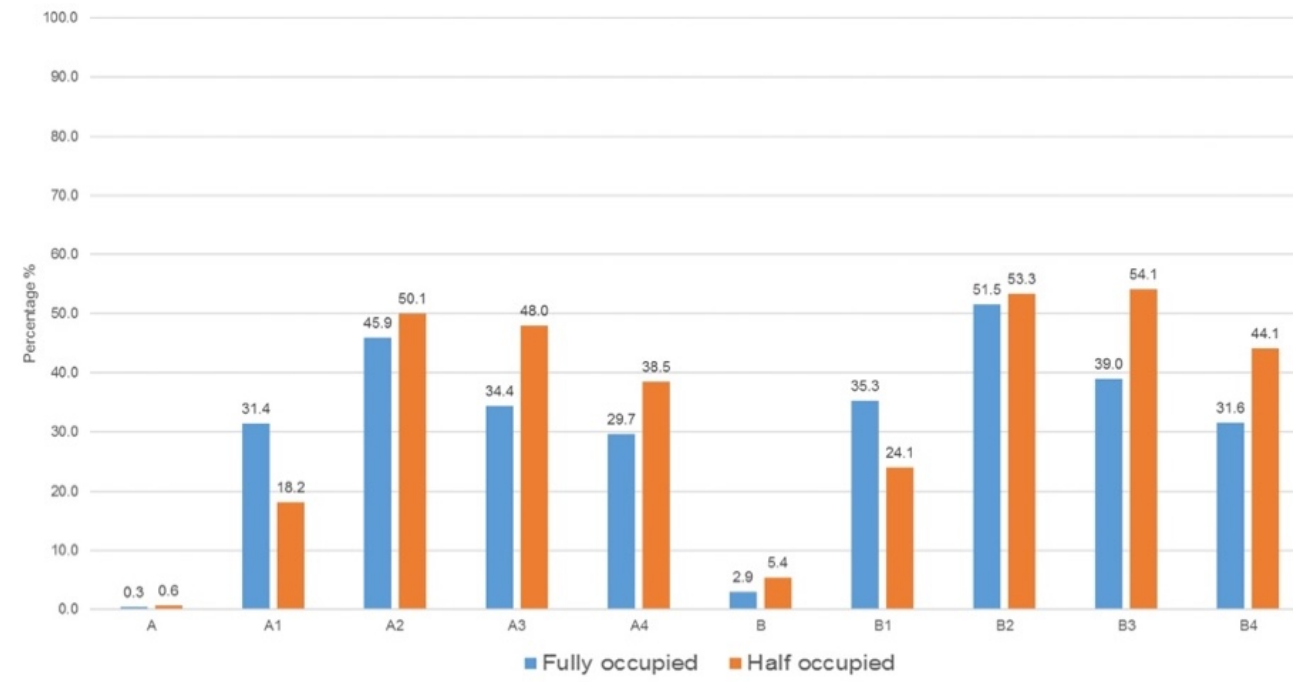

Figure 5. Frequencies of Thermal Comfort Achievement During Summer Source: Indarti, 2016 


\section{CONCLUSIONS}

The initial concept design involves the environment of the site by delivering daylighting and natural ventilation through the funnel in the debating chamber (the 'Siambr'). The building itself is certified excellent in leading building rating tools in the UK, BREEAM for the innovative environmental features.

The daylight assessment indicates that the current condition (case A) of the debating chamber was under-lit, proved by the average daylight factor which was only $4.08 \%$ that is under 5\% from the benchmark. After expanding the transparent wall of the funnel, the average daylight factor had increased by $0.98 \%$. However, the improvement of average daylight factor inside the debating is theoretically conducted by removing the wind cowl and increasing the average daylight factor to $13.07 \%$ to achieve the visual comfort for the occupants.

As a consequence of the act on removing the wind cowl, a natural ventilation system inside the debating chamber is investigated to generate the air flow rate for further study of thermal comfort. The simulation for natural ventilation is conducted by assuming two cases i.e. using wind cowl (case A) as the base case and not using wind cowl (case B) as the result of improving daylight conditions inside the chamber altogether with modifying the inlet effective aperture to find the optimum inlet aperture for the debating chamber. The result shows that the air flow rate in each case is slightly reduced. However, the result states that each case achieved the requirement for fresh air but did not achieve the requirement for cooling.

Furthermore, the investigation of thermal comfort is conducted to comprehend the effect of using and not using wind cowl as the continuation of the proposed improvement for the debating chamber. The results illustrate that without using wind cowl the debating chamber performed better which is proved by the increasing frequencies of achieved thermal comfort by $4.08 \%$ in the summer during working hours with the optimum effective aperture inlet $50 \%$.

In summary, delivering natural resources as a response of the environment potentially mitigates the energy consumption of a building due to the decreasing dependence on the active system (heating, cooling and lighting demand). However, the engagement of the optimisation of natural resources should be delivered in a holistic approach. Any improvement of daylight conditions inside the space automatically affects natural ventilation and thermal performance and vice versa.

\section{REFERENCES}

Acosta, I, Munoz, C, Campano, M and Navarro, J. (2015) Analysis of daylight factors and energy saving allowed by windows under overcast sky conditions, Renewable Energy, 77, 194-207, Elsevier, Amsterdam.

Acosta, I, Navarro, J and Sendra, J. (2014) Lighting design in courtyards: Predictive method of daylight factors under overcast sky conditions, Renewable Energy, 71, 243-254, Elsevier, Amsterdam. 
Architecture Week. (2016) Assembly by Rogers,

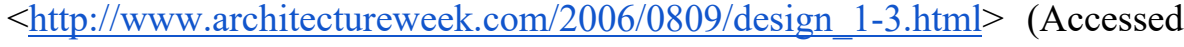
on 8 February 2016).

Baker, N and Steemers, K. (2002) Daylight Design of Buildings, James \& James, London.

BRE Global. (2016) Scoring and Rating, $<\underline{\text { https://www.breeam.com/domrefurbmanual/content/03scoring/01scoring_a }}$ nd rating.htm $>$ (Accessed on 16 May 2016).

Building Research Establishment (BRE). (2016) HEA 01 Visual Comfort, $<$ https://www.breeam.com/nc2018preview/Content/05 health/hea01 nc.htm $>$ (Accessed on 24 October 2020).

Butcher, K and Craig, B. (2015) Environmental design : CIBSE guide A, Chartered Institution of Building Services Engineers, London.

Chartered Institution of Building Services Engineers. (1999) Daylighting and Window Design, CIBSE, London.

Chel, A, Tiwari, G and Chandra, A. (2009) A model for estimation of daylight factor for skylight: An experimental validation using pyramid shape skylight over vault roof mud-house in New Delhi (India), Applied Energy, 86, 2507-2519, Elsevier, Amsterdam.

Clarke, J. (2015) Energy Simulation in Building Design, Routledge, London.

Emmerich, S, Axley, J and Dols, S. (2001) Natural Ventilation Review and Plan for Design and Analysis Tools, National Institute of Standards and Technology, Gaithersburg.

Fishlock, T and Molyneux, A. (2010) Senedd, Graffeg, Cardiff.

Ghiaus, C and Allard, F. (2016) Natural Ventilation in the Urban Environment: Assessment and Design, Routledge, London.

Heiselberg, P. (2004) Natural Ventilation Design, International Journal of Ventilation, 2, 295-312, Taylor \& Francis, London.

Hopkinson, R, Petherbridge, P and Longmore, J. (1966) Daylighting, Heinmann, London.

Olgyay, V. (1963) Design with Climate Bioclimatic Approach to Architectural Regionalism, Princeton University Press, Princeton.

Park, H, Lee, M, Kang, H, Hong, T and Jeong, J. (2016) Development of a new energy benchmark for improving the operational rating system of office buildings using various data-mining techniques, Applied Energy, 173, 225-237, Elsevier, Amsterdam.

Rennie, D and Parand, F 1998, Environmental design guide for naturally ventilated and daylit offices, Construction Research Communications, London.

Rizal, Y, Robandi, I and Yuniarno, E. (2016) Daylight Factor Estimation Based on Data Sampling Using Distance Weighting, Proceeding for 3rd International Conference on Power and Energy Systems Engineering, 8-12 September 2016, Kitakyushu.

Schwartz, Y and Raslan, R. (2013) Variations in results of building energy simulation tools, and their impact on BREEAM and LEED ratings: A case study, Energy and Buildings, 62, 350-359, Elsevier, Amsterdam. 
Shakespeare, R, Larson, G and Ehrlich, C. (2005) Rendering with Radiance : the Art and Science of Lighting Visualization, Space and Light, Davis.

Valinejadshoubia, M, Heidarib, S and Zamanib, P. (2019) The impact of temperature difference of the sunny and shady yards on the natural ventilation of the vernacular buildings, Journal of Building Engineering, 26, 100880, Elsevier, Amsterdam. 
Indarti: THE HOLISTIC PERFORMANCE OF AN ENVIRONMENTAL APPROACH: SENEDD CASE STUDY

This Page is Intentionally Left Blank 